\title{
International Journal of Materials Science and Engineering
}

\section{CONTENTS}

\section{Volume 1, Number 2, December 2013}

Finite Element Analysis for Connection Mechanism in Macro-Micro Platform .50

Lufan Zhang, Zhili. Long, Longsheng Nian, and Jiwen Fang

Influenced of the Donor-Acceptor Interface Morphology on Electrical Properties of Organic Solar Cells Based on Soluble TsNiPc

MuhamadSaipul Fakir, KhaulahSulaiman, and FahmiFariq Muhammad

Cluster Based Energy Routing System for Wireless Sensor Networks

Ifrah Farrukh Khan and Muhammad Younus Javed

An Electromagnetic Micro Power Generator Based on Mechanical Frequency Up-Conversion

Vida Pashaei and Manouchehr Bahrami

Acoustic-Based Electrodynamic Energy Harvester for Wireless Sensor Nodes Application

Farid Ullah Khan and Izhar

Influence of SU8 PhotoPolymer for Silicon RFMEMS Packaging Applications

Srinivasa Reddy Kuppireddi, Sayanu Pamidighantam, and Oddvar Søråsen

Analysis and Simulation of Serpentine Suspensions for MEMS Applications

M. Bedier and Roshdy AbdelRassoul

Water and Electronic Simulated Experiment Study of Volume Fracturing Horizontal Wells in the Tight Oil Reservoir.

Baojian Du, Linsong Cheng, and Liu Jia

BLEVE Performance of Fire Protection Coating Systems on Dangerous Goods Tanks in a Test Fire

Christian Sklorz, Frank Otremba, and Christian Balke

Biodiesel Production Based on Waste Cooking Oil (WCO)

Nor Hazwani Abdullah, Sulaiman Haji Hasan, and Nurrul Rahmah Mohd Yusoff

Process to Produce Biodiesel Using Jatropha Curcas Oil (JCO)....

Nurrul Rahmah Binti Mohd Yusoff, Sulaiman bin Hj Hasan, and Nor Hazwani binti Abdullah

Gear Material Selection using Complex Proportional Assessment and Additive Ratio Assessment-based Approaches: A Comparative Study.....

Prasenjit Chatterjee and Shankar Chakraborty

Asymmetrical Molecular Junctions with different Alligator Clips 112

Rupan Preet Kaur, Ravinder Singh Sawhney, and Derick Engles 
Structural, Optical and Electrical Properties of NiO Thin Films Prepared by Low Cost Spray Pyrolysis Technique.

S. Sriram and A. Thayumanavan

Optimization of Steam Turbine Casing for Static Loading Condition 122

Laxminarayan.k, M. Venkatarama Reddy, and Kumar 